\title{
Retraction Note to: MicroRNA-322 Cluster Promotes Tau Phosphorylation via Targeting Brain-Derived Neurotrophic Factor
}

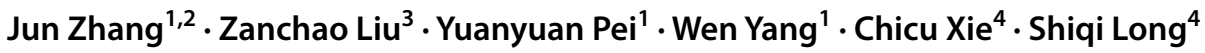

Published online: 25 June 2020

(c) Springer Science+Business Media, LLC, part of Springer Nature 2020

\section{Retraction to: Neurochemical Research (2018) 43:736-744 https://doi. org/10.1007/s11064-018-2475-1}

The Editors have retracted this article [1] following an investigation conducted by the journal. After publication concerns were raised regarding interpretation of the data presented in Fig. 4. The Editors requested additional data and clarification to confirm interpretation of data results. After further review, the Editors found that the additional data were not adequate to support the conclusion of the article and that P-values for the additional data were based on improper statistical analyses. With more appropriate statistical analysis, the reported effects for miR-322 and BDNF were not statistically significant. Dr. Chichu Xie agrees to this retraction. None of the other authors have responded to any correspondence from the publisher about this retraction.

\section{Reference}

1. Zhang J, Liu Z, Pei Y (2018) MicroRNA-322 cluster promotes tau phosphorylation via targeting brain-derived neurotrophic factor. Neurochem Res 43:736-744. https://doi.org/10.1007/s1106 4-018-2475-1

Publisher's Note Springer Nature remains neutral with regard to jurisdictional claims in published maps and institutional affiliations.

The original article can be found online at https://doi.org/10.1007/ s11064-018-2475-1.

Shiqi Long

767446430@qq.com

1 Department of Pathology, The Affiliated Hospital of Guizhou Medical University, Guiyang 550004, People's Republic of China

2 Department of Pathology, Graduate School of Medicine, Guizhou Medical University, Guiyang 550004, People's Republic of China

3 The Shijiazhuang Second Hospital of Hebei Province, Shijiazhuang 050051, People's Republic of China

4 Department of Immunology, Basic School of Medicine, Guizhou Medical University, Guiyang 550004, People's Republic of China 